2019-04-24

\title{
Observations on the relationship
} between the dietetic Objective Structured Clinical Exam and placement outcome.

\author{
Parkin, Tracey
}

http://hdl.handle.net/10026.1/13497

10.1111/1747-0080.12537

Nutrition and Dietetics

Wiley

All content in PEARL is protected by copyright law. Author manuscripts are made available in accordance with publisher policies. Please cite only the published version using the details provided on the item record or document. In the absence of an open licence (e.g. Creative Commons), permissions for further reuse of content should be sought from the publisher or author. 


\section{Observations on the relationship between the Dietetic Objective Structured}

\section{Clinical Exam and placement outcome.}

\section{Abstract}

\section{$4 \quad$ Aims}

5 Objective Structured Clinical Examinations (OSCEs) are used extensively in medical 6 education to prepare students for the clinical setting. Use in dietetic education is still

7 relatively new and relationships to placement outcomes are unknown. The aim of this

8 review was to explore eleven years of OSCE and placement data to answer: Does the

9 OSCE predict dietetic placement outcome? and What are the student perceptions of the benefits of OSCE in preparation for practice?

\section{Methods}

12 Data collected retrospectively from 328 students between 2006-2017 who had completed their final year OSCE and placement. Aggregate OSCE mark and mean marks obtained in active and passive OSCE stations, were compared to placement outcome. Evaluation questionnaires completed by students at the end of the OSCE were

16 collated.

\section{Results}

18 Aggregate marks achieved in OSCE stations were significantly different in students who passed $($ mean 63.24, SD7.94), struggled $($ mean $=58.25$, SD8.82) or failed $($ mean $=$ 57.31, SD8.28) placement, $p<0.001$. Majority of students perceived the OSCE as a

21 meaningful and fair assessment (92\%) that helped to prepare them for practice (82\%). 
23 The OSCE provides a meaningful assessment of dietetic student skills in preparation for practice. Aggregate OSCE marks provide a consistent indicator of students who are likely to struggle in practice.

Key words: Assessment, competence, dietetics, education, evaluation, OSCE

\section{Introduction}

Medical education has utilised Objective Structured Clinical Exams (OSCEs) for many years to develop communication and clinical skills ${ }^{1}$ in preparation for the clinical setting. ${ }^{2-3}$ OSCEs are reported to stimulate learning and greater achievement of specific clinical competence. ${ }^{4}$ It is well documented that the OSCE is labour intensive, time consuming and therefore an expensive examination to run ${ }^{5}$ however, the ability to prepare students for the practice setting has been identified as a key strength of this examination ${ }^{2}$ as well as its flexibility in design and structure. ${ }^{6}$

There is a wealth of data supporting the use of the OSCE to prepare medical students for practice, ${ }^{7}$ in contrast, OSCE assessments in dietetics is relatively new. ${ }^{8}$ Consequently, there is little reported data on whether the OSCE has the same benefits in preparing dietetic students for placement. ${ }^{8}$ In addition, the range of skills assessed in a dietetic OSCE may differ from those assessed in medical, nursing and other professional OSCEs. ${ }^{4-8}$ Although communication skills are core to all professional assessments, remaining skills tested will vary due to the nature of the work undertaken by the different professions. For example: dietetic students may be assessed on 
43 anthropometric assessments, but hands on examination, use of equipment or clinical

44 procedures as seen in nursing, medical OSCEs is not required.

45 The design of the dietetic OSCE involves mapping of specific skills against the examination format as described by others. ${ }^{9-11}$ The OSCE was originally set up as six

47 discrete 10- minute stations, consisting of two active and four passive stations ${ }^{10}$ using a

48 multi- station design ${ }^{12}$ to test specific clinical skills. Active stations focus on

49 communication skills, knowledge and application whilst passive stations explore

50 practical skills around knowledge application, understanding and dietary

51 manipulation. ${ }^{11}$

52 Actors using standardised scripts play the part of patients in the active OSCE stations ${ }^{13}$.

53 Experienced academic or clinical examiners assess active stations using a standardised

54 scoring sheet, which assesses the knowledge and communication skills utilised by students. Actors and examiners meet prior to the examination to run through the scripts, discuss standard answers and clarify scoring to ensure consistency during the

57 examination. In addition, moderation occurs at the active stations to ensure consistency with actor's delivery throughout the examination and marking process.

59 The passive stations assess clinical skills such as assessment, implementation and

60 intervention. For example, a clinical scenario and data for planning a dietetic

61 intervention, such as biochemistry, growth charts and food diaries maybe provided.

62 Allowing assessment of student's ability to interpret provided data; identify areas in the

63 diet requiring manipulation, addressing issues raised, as well as indicating appropriate

64 alternative food choices. Skills required to carry out these tasks are developed and 
practiced in class helping to prepare students for both the OSCE examination and the final practice. ${ }^{14}$

Students move from station to station, a system of bells and buzzers indicates when the student should move to the next station. Incorporation of feedback from examiners, students and actors ${ }^{10}$ over the years has resulted in a number of changes. Key skills tested from the initial OSCE design of six 10- minute stations were amalgamated into four 15- minute stations, which included two passive and two active stations. Integration of skills into longer OSCE stations more accurately reflect a real life scenario. ${ }^{14}$ For example, having more time in the active station with the actors allows students time to move through the Model and Process for Nutrition and Dietetic Practice (MPNDP), ${ }^{15}$ as they would in a real clinical situation, rather than focusing on one discrete aspect of the consultation. In addition, integration of skills better reflects the growing competency and skill development of a final year student ${ }^{16}$ and allows better assessment of communication and clinical reasoning skills. ${ }^{17-18}$ Examiners test clinical reasoning skills further at the end of the active station by asking a standard question.

Placement assessment requires students to demonstrate competencies in the following areas: the MPNDP, ${ }^{15}$ communication, reflection, professionalism and time management. The OSCE examination therefore specifically tests skills related to the MPNDP, ${ }^{15}$ communication, professionalism and time management in preparation for placement.

The use of the OSCE with Australian and UK dietetic students prior to their first practice experience has indicated a potential for the OSCE to predict those students who may have difficulties on their initial placement. ${ }^{8}$ However, first placements or early 
placements are likely to be the most challenging for students as experiences in these settings will all be new, including opportunities for students to start working with patients and applying theory into practice. Student performance on final year placement and final year OSCE however may differ considerably, as students will have a greater knowledge base, prior placement experience and opportunities to practice and develop skills further.

This paper reports on data collected over the last 11 years and will review final year OSCE marks and the relationship to dietetic students' progress on final year placements. It includes an exploration of the relationship between active and passive station marks, student outcome on the final placement and student's perception of this examination.

\section{Methods}

\section{Ethical approval was provided by the Faulty Research Ethics and Integrity}

Committee. Data was collected retrospectively on students from 2006 to 2017, who had completed both the final year OSCE and undertaken the final placement. OSCE marks and placement outcome were collated. Student feedback following the OSCE was collated onto an excel spreadsheet. Feedback from students following OSCE is a standard process; with anonymous feedback from student's actors and examiners, being used annually to modify OSCE design and delivery. Feedback is collated at the end of the OSCE; it includes questions that explore perception of the OSCE. Questionnaire responses range from strongly agree, agree, neither disagree nor agree, disagree, strongly disagree. Percentage responses were collated for agreement and disagreement, responses coded as; neither agree nor disagree, where coded as disagreement.

Achievement on placement was split into three categories: 
1. Pass, achieved all placement learning outcomes.

2. Struggled, required additional support from placement team before passing placement.

Data on students requiring extra time and/or support from placement team is routinely recorded at the time of placement and was used to code students in this category.

3. Failed, did not achieve placement learning outcomes despite additional support from placement team.

Active stations link into placement competencies around communication, and application of the MPNDP ${ }^{15}$ and professionalism. Students may receive a food record and GP letter to review before starting the consultation. Information gathered during the consultation guides assessment, diagnosis and appropriate provision of information to the actor in a professional and competent manner.

Passive stations link into placement competencies relating to the MPNDP ${ }^{15}$ and involve discriminatory skills, interpretation of data and practical application of food knowledge skills. Active and passive stations are both time limited linking into the placement competency around time management.

In 2010 following programme redesign, the timing of the OSCE changed from a post to a pre-placement assessment, and the number of OSCE stations were reduced to four 15minute stations (two active and two passive). Data from 2006/7 to 2009/10 relates to the OSCE being undertaken after placement and data from 2010/11 to 2016/17 relates to the OSCE being undertaken prior to clinical placement. 
133 OSCE station marks are reported as percentages. Descriptive statistics are provided for 134 the aggregate OSCE mark, and the mean active and mean passive station marks from 135 2006-2017. Student feedback was explored using percentage response to evaluations. 136 Inferential statistics were carried out using SPSS, version 21 (SPSS Inc, Chicago, IL, 137 USA). Data were tested for normality using the Shapiro-Wilk's test.

Differences in OSCE active and passive station marks and placement outcome were explored using one way ANOVA and independent t-test. The level of significance was 140 set at $p<0.05$.

\section{Results}

142 A total of 328 students undertook the OSCE from 2006-2017. The aggregate score 143 achieved for the OSCE was $62.42 \%$ (SD 8.29).

144 One way ANOVA indicates significant differences in the aggregate OSCE mark for students who passed, struggled or failed placement $\mathrm{F}=(2,325)=9.842, p<0.001$ (see 146 Table 1).

\section{INSERT TABLE 1 HERE}

Table 1: Aggregate marks achieved in OSCE and placement outcome

150 The difference in aggregate OSCE mark for students who struggled and students who failed placement was not significant. Of those students identified as requiring additional support from the placement team $(n=22+26)$, nearly half $46 \%(22 / 48)$ went on to 153 achieve the final placement. 
Data was reviewed to explore timing of the OSCE (pre-placement and post-placement), and impact on relationship between aggregate OSCE mark and placement outcome. Regardless of OSCE timing, aggregate OSCE mark for students who passed placement and those who failed placement remains significantly different (Table 2).

\section{INSERT TABLE 2 HERE}

Table 2: Aggregate OSCE mark for Post-Placement and Pre -placement compared

\section{to placement outcome}

Data for active station OSCE marks and placement outcome were explored for pre and post-placement timings. There were 2 years when the post-placement OSCE ran with only 1 active station, 2008/9 and 2009/10. Data for these two years was removed to allow comparison of mean active station marks and placement outcome, see Table 3.

\section{INSERT TABLE 3 HERE}

\section{Table 3: Mean active station marks and placement outcome}

Regardless of post and pre-placement OSCE timing, mean active station mark for students who passed placement and those who failed placement remains significantly different.

How many students failing active stations go onto fail placement? Regardless of post and pre-placement OSCE timing the percentage of student's failing one active station is consistent, post-placement was 9\% (6/65) and pre-placement was 10\% (19/190). Of those students failing one active station, 64\% (16/25) went on to pass the placement.

Data for passive station OSCE marks and placement outcome were explored for pre and post-placement timings. Pre-placement OSCE; there was no significant difference in 
passive station marks achieved by students who, passed, struggled or failed placement,

177 see Table 4.

INSERT TABLE 4 HERE

Table 4: Mean passive station marks and placement outcome

180

A total of 312 students completed the evaluation questionnaires equating to a $95 \%$

(312/328) response rate. The data were separated into two categories, students completing the OSCE after placement and students completing OSCE before placement, see Table 5.

Table 5: Student evaluation of the OSCE examination

Undertaking the OSCE pre-placement as compared to post- placement resulted in higher agreement with all questions. Students perceived the OSCE to be stressful regardless of timing however, the last three years indicates a downward trend in students perceived level of stress with responses of $97 \%, 83 \%$ and $70 \%$ being recorded.

\section{Discussion}

This retrospective review of final year OSCE and placement data has identified a significant difference in the aggregate OSCE mark and placement outcome. The mean active station mark was significantly different in students who passed, and students who failed placement however, the passive station marks lost significance with placement outcome when the OSCE moved to a pre-placement assessment. Student evaluation supported the view that the OSCE is a meaningful and fair assessment of skills, which 
prepare students for practice. The data presented here is unique in that it provides a longitudinal perspective that illustrates a consistent relationship between dietetic students' performance in the OSCE and dietetic placement outcome. This data supports and builds on findings from other studies. Highlighting the potential of the dietetic OSCE to identify dietetic students who may require additional support on placement. ${ }^{9}$ In addition, findings indicate that the OSCE not only has a place in identifying first year dietetic students who may struggle on placement ${ }^{9}$ but also final year dietetic students completing the final placement.

Although the timing of the OSCE has changed, from post to pre-placement, relationship between OSCE performance and placement outcome remains significant. The OSCE comprises of active and passive stations, the mean active station marks were a significant indicator of students' achievement on placement and provides further evidence to support this type of examination to test the application of knowledge and communication skills prior to placement. A small number of dietetic students (10\%) regularly fail one of the active stations, failing one active station is not indicative of failing placement. Obtaining a lower mean mark in the active stations is however, linked to placement failure, suggesting a more generalised problem with applying communication skills and knowledge to support clinical reasoning skills.

Performance at active stations was variable with large deviations in the marks achieved. Knowledge and confidence ${ }^{19}$ may inhibit performance resulting in poor demonstration of communication skills. When knowledge and confidence are high, better communication skills maybe demonstrated, communication skills and knowledge are 
224 closely linked ${ }^{20}$ resulting in case based variability of students' ability to communicate to actors in OSCEs. ${ }^{21}$ This may account for the variability seen in active station marks in the dietetic OSCE.

In addition, medical OSCEs that assess whole tasks, where students examine patients on a diagnosed complaint rather than discrete skills, increased students' use of diagnostic reasoning skills. ${ }^{17}$ This may also be the case for the dietetic active OSCE stations, with the move from discrete skill testing, to longer consultations that reflect real life scenarios. ${ }^{22}$ On placement, students need to demonstrate their ability to apply clinical reasoning skills, to work through the MPNDP ${ }^{15}$ with a variety of patients. Lack of ability to transfer these skills from one patient to another, to demonstrate safe clinical reasoning will result in placement failure. Lower mean marks achieved in the active stations are therefore indicative of poor clinical reasoning skills.

Passive stations test skills against paper exercises, actors are not involved. Passive station marks lost significance with placement outcome when the OSCE moved to a pre-placement assessment. Completing the OSCE post-placement allows students time to practice and consolidate skills on placement. The significant association between placement outcome and passive station marks post-placement may therefore reflect poor consolidation of these skills on placement. Alternatively, anxiety of undertaking the practical exam following a failed placement may result in poor performance at passive stations. When passive stations occur prior to placement, attainment of skills are more likely to reflect students learning and acquisition of skills in University. This may account for the lack of significance between placement outcome and passive station 
marks when the OSCE moved from post to pre-placement assessment. In addition, the resulting lack of significance between placement outcome and passive station marks suggests that skills examined are different from those in active stations. Passive stations test a discrete range of skills, patients are not involved, this may contribute to the lack of association between pre-placement passive station marks and placement outcome, as complex clinical reasoning skills are not specifically tested. ${ }^{17}$

254

Moving the OSCE to pre-placement has altered students' perception of the relevance of this examination, with the majority of students reporting the OSCE to be a more meaningful and fair assessment of skills. Students increasingly see this examination as a way to help them manage stressful events. Similar to findings in dental students, ${ }^{23}$ the majority of dietetic students indicated that they found the OSCE stressful. Interestingly, perceived stress in dental students did not affect student performance. ${ }^{23}$ Hong ${ }^{24}$ however has suggested that student's anxiety about OSCEs may influence their ability to perform during the OSCE. Examination stress may affect their individual working memory "the ability to hold in information and manipulate it" 25 (p93) the combined effect of this could result in a poor demonstration of skills within the active OSCE stations. In nursing students, anxiety has been reduced by providing video exemplars prior to the OSCE, however this did not impact on students overall

267 performance. ${ }^{26}$ Suggesting that anxiety is not the only factor impacting student 268 performance in the OSCE.

Poor time management and anxiety are commonly cited reasons for students struggling on placement and requiring additional time. ${ }^{22}$ Dietetic students use timed sessions to 
develop confidence in information retrieval, attainment and performance ability prior to sitting the OSCE. ${ }^{27}$ This may help to improve students' perception of control and in combination with techniques to reduce student anxiety, may help to improve performance long term. ${ }^{28}$ In addition, OSCE briefings allow students to become familiar with the process. These measures may have contributed to the downward trend in students reported stress levels with the dietetic OSCE examination over the last three years.

Providing feedback after an OSCE affects the affective domain of learning and improves students' ability to relate OSCE activities to clinical practice. ${ }^{2}$ Video/audio recording also provides a valuable method to further support students in reflecting on skill use in preparation for the OSCE and future placement. ${ }^{29}$ Currently we offer dietetic students audio/video recording as an optional method of support when developing skill use, with audio- recording routinely used for some skill development sessions. Routine use of simulation strengthens links between theory and practice, as well as developing confidence ${ }^{30}$ and self-efficacy ${ }^{31}$ in use of communication skills. Practical sessions also help support knowledge acquisition, ${ }^{32}$ in preparation for the OSCE, setting theory exam close to the OSCE helps strengthen this area further.

A retrospective review of data does carry some limitations as it is unable to relate individual feedback to student performance or explore variations in placement performance and skills utilised with student perceptions. However, despite these drawbacks and the minor changes that have occurred to the OSCE over the last eleven years a consistent pattern has emerged. The data presented indicates that the OSCE 
provides a successful assessment of dietetic students' practical skills required for placement. The OSCE has a valid role in preparing dietetic students for placement and identifying students likely to struggle and therefore require additional support.

In summary, this retrospective review highlights an association between the aggregate OSCE mark, in particular mean active station marks and dietetic students who are likely to fail placement. The OSCE provides a meaningful assessment of practical clinical skills, and is a useful indicator of dietetic students' performance in practice, indicating students who are likely to require additional support on placement.

\section{References:}

1. Harden RM, Stevenson M, Downie WW, Wilson GM. Assessment of clinical competence using objective structured examination. Br Med J 1975; 1 (5955): 44751.

2. Casey PM, Goepfert AR, Espey EL, Hammoud MM, Kaczmarczyk JM, Katz NT, Neutens JJ, Nuthalapaty FS, Peskin E, Association of Professors of Gynecology and Obstetrics and Undergraduate medical Education Committee. To the point: reviews in medical education--the Objective Structured Clinical Examination. Am J Obstet Gynecol 2009; 200 (1): 25-34.200.

3. Jünger J, Schäfer S, Roth C, Schelberg D, Friedman Ben-David M, Nikendei C.. Effects of basic clinical skills training on objective structured clinical examination performance. Med Educ 2005; 39 (10): 1015-20. 
4. Schoonheim-Klein ME, Habets LL, Aartman IH, van der Vleuten CP, Hoogstraten J, van der Velden U. Implementing an Objective Structured Clinical Examination (OSCE) in dental education: effects on students' learning strategies. Eur J Dent Educ 2006; 10 (4): 226-35.

5. . Reznick RK, Smee S, Baumber JS, Cohen R, Rothman A, Blackmore D, Bérard M. Guidelines for estimating the real cost of an objective structured clinical examination. Acad Med 1993; 68 (7): 513-7.

6. Patrício MF, Julião MF \& Carneiro AV. Is the OSCE a feasible tool to assess competencies in undergraduate medical education? Medical Teacher 2013; 35 (6): 503-514.

7. Khan KZ, Ramachandran S, Gaunt K, Pushkar P. The Objective Structured Clinical Examination (OSCE): AMEE Guide No. 81. Part I: an historical and theoretical perspective. Med Teach 2013; 35 (9): 1437-46.

8. Hawker JA, Walker K Z, Barrington V, Andrianopoulos N. Measuring the success of an objective structured clinical examination for dietetic students. J Hum Nutr Diet 2010; 23 (3): 212-6.

9. Hawker J \& Walker K. An Objective Structured Clinical Examination to assess preclinical skills. Nutr Diet 2010; 67 (2): 102-105.

10. Lambert L, Pattison DJ, de Looy AE. Dietetic students' performance of activities in an objective structured clinical examination. J Hum Nutr Diet 2019; 23 (3): 224-9.

11. Pender FT, de Looy AE. The testing of clinical skills in dietetic students prior to entering clinical placement. . J Hum Nutr Diet 2004; 17 (1): 17-24. 
12. Rushforth HE. Objective structured clinical examination (OSCE): Review of literature and implications for nursing education. Nurse Educ Today 2007; 27 (5): $481-490$.

13. Adamo G. Simulated and standardized patients in OSCEs: achievements and challenges 1992-2003. Med Teach 2003; 25 (3): 262-70.

14. Major DA. OSCEs--seven years on the bandwagon: the progress of an objective structured clinical evaluation programme. Nurse Educ Today 2005; 25 (6): $442-54$.

15. British Dietetic Assoication (BDA). Model and Process for Nutrtion and Dietetic Practice [internet] UK. British Dietetic Assocaition: 2016 [updated; May 2016]. Available from: https://www.bda.uk.com/publications/professional/model_and_process_for_nutritio n_and_dietetic_practice_(accessed November 2017)

16. Ross M, Carroll G, Knight J, Chamberlain M, Fothergill-Bourbonnais F, linton J. Using the OSCE to measure clinical skills performance in nursing. $J$ Adv Nurs 1988; 13 (1): 45-56.

17. Lafleur A, Côté L, Leppink J. Influences of OSCE design on students' diagnostic reasoning. Med Educ 2015; 49 (2): 203-14.

18. Traynor M, Galanouli D, Rice B, LynnF. Evaluating the objective structured long examination record for nurse education. Br J Nurs 2016; 25 (12): 681-7.

19. Lundberg KM. Promoting Self-confidence in Clinical Nursing Students. Nurse Educ 2008; 33 (2): 86-89. 
20. Laidlaw TS, Kaufman DM, Mac Leod H, van zanten S, Simpson D, Wrixton W. Relationship of resident characteristics, attitudes, prior training and clinical knowledge to communication skills performance. Med Educ 2006; 40 (1): 18-25.

21. Guiton G, Hodgson CS, Delanshere G, Wilkerson L. Communication Skills in Standardized-Patient Assessment of Final-Year Medical Students: A Psychometric Study. Advances in Health Sciences Education 2004; 9 (3): 179-187.

22. Luhanga FL, Larocque S, MacEwan L, Gwekwerere YN, Danyluk P. Exploring the Issue of Failure to Fail in Professional Education Programs: A Multidisciplinary Study. Journal of University Teaching \& Learning Practice 2014; 11 (2): Available at:http://ro.uow.edu.au/jutlp/vol11/iss2/3

23. Brand HS, Schoonheim-Klein M. Is the OSCE more stressful? Examination anxiety and its consequences in different assessment methods in dental education. Eur J Dent Educ 2009; 13 (3): 147-53.

24. Hong, E. Test anxiety, perceived test anxiety, and test performance: Temporal patterns of their effects. Learn Individ Differ 1999; 11 (4): 431-447.

25. Owens M, Stevenson J, Hadwin JA, Norgate R. When does anxiety help or hinder cognitive test performance? The role of working memory capacity. Br J Psychol 2014; 105 (1): 92-101.

26. Massey D, Byrne J, Higgins N, Weeks B, Shuker MA, Coyne E, Mitchell M, Johnston ANB. Enhancing OSCE preparedness with video exemplars in undergraduate nursing students. A mixed method study. Nurse Educ Today 2017; 54: 56-61. 
27. National Council of State Boards of Nursing. Report of Findings from The Effect of High-Fidelity Simulation on Nursing Students' Knowledge and Performance: A Pilot Study. Research Brief 2009; 40. Chicago: Hicks FD, Coke L, Li S.

28. Putwain DW,Aveyard B. Is Perceived Control a Critical Factor in Understanding the Negative Relationship Between Cognitive Test Anxiety and Examination Performance? Sch Psychol Q 2018; 33 (1): 65-74.

29. Paul F. An exploration of student nurses' thoughts and experiences of using a videorecording to assess their performance of cardiopulmonary resuscitation (CPR) during a mock objective structured clinical examination (OSCE). Nurse Educ Pract 2010; 10 (5): 285-90.

30. Lendahls L \& Oscarsson MG. Midwifery student's experiences of simulation and skills training. Nurse Educ Today 2017; 50 :12-16.

31. Kameg K, Howard VM, Clochesy J, Mitchell AM, Suresky JM. The impact of high fidelity human simulation on self-efficacy of communication skills. Issues Ment Health Nurs 2010; 31 (5): 31:315-23.

32. Mitchell ML, Henderson A, Groves M, Dalton M, Nutly D. The objective structured clinical examination (OSCE): Optimising its value in the undergraduate nursing curriculum. Nurse Educ Today 2009; 29 (4): 398-404. 
Table 4: Aggregate marks achieved in OSCE and placement outcome

\begin{tabular}{|cccc|}
\hline $\mathrm{N}=328$ & $\begin{array}{c}\text { Passed } \\
\text { Placement } \\
\mathrm{n}=280\end{array}$ & $\begin{array}{c}\text { Struggled on } \\
\text { placement } \\
\mathrm{n}=22\end{array}$ & $\begin{array}{c}\text { Failed } \\
\text { placement } \\
\mathrm{n}=26\end{array}$ \\
\hline Mean OSCE mark (SD) & $63.24(7.94)$ & $58.25(8.82)^{*}$ & $57.19(8.28)^{* *}$ \\
\hline
\end{tabular}

* Independent t-test indicates significant difference between students who passed placement and those who struggled on placement, $p=0.005$

** independent t-test indicates significant difference between students who passed placement and those who failed placement, $p<0.001$ 
Table 5: Aggregate OSCE mark for Post-Placement and Pre -placement compared to placement outcome

\begin{tabular}{|ccccc|}
\hline N=328 & $\begin{array}{c}\text { Passed } \\
\text { placement }\end{array}$ & $\begin{array}{c}\text { Struggled on } \\
\text { placement }\end{array}$ & $\begin{array}{c}\text { Failed } \\
\text { placement }\end{array}$ & $\begin{array}{c}P \\
\text { value }\end{array}$ \\
\hline Post-placement OSCE mean (SD) & $62.71(7.80)$ & $54.82(5.51)^{*}$ & $55.07(5.84)^{* *}$ & 0.001 \\
$\mathrm{n}=138$ & $\mathrm{n}=116$ & $\mathrm{n}=10$ & $\mathrm{n}=12$ & \\
Pre-placement OSCE mean (SD) & $63.61(8.12)$ & $61.10(10.21)$ & $59.00(9.77)^{* *}$ & 0.101 \\
$\mathrm{n}=190$ & $\mathrm{n}=164$ & $\mathrm{n}=12$ & $\mathrm{n}=14$ & \\
\hline
\end{tabular}

*Independent t-test indicates significant difference between students who passed placement and students who struggled $p=0.002 * *$ Independent t-test indicates significant difference between students who passed placement and those who failed placement; post-placement $p=0.001$, preplacement $p=0.047$ 
Table 6: Mean active station marks and placement outcome

\begin{tabular}{|lcccc|}
\hline $\begin{array}{l}\text { Mean Active } \\
\text { station marks }\end{array}$ & $\begin{array}{c}\text { Passed } \\
\text { placement }\end{array}$ & $\begin{array}{c}\text { Struggled on } \\
\text { placement }\end{array}$ & $\begin{array}{c}\text { Failed } \\
\text { placement }\end{array}$ & P value \\
\hline $\begin{array}{l}\text { Overall mean } \\
\text { active stations (SD) }\end{array}$ & $66.72(10.04)$ & $61.50(13.49)$ & $56.00(11.74)^{* * *}$ & 0.001 \\
$\quad \mathrm{n}=220$ & $\mathrm{n}=16$ & $\mathrm{n}=19$ & \\
$\begin{array}{l}\text { Post-placement OSCE } \\
\text { Active stations (SD) }\end{array}$ & $67.14(9.13)$ & $54.38(7.47)^{*}$ & $52.90(8.39)^{* *}$ & 0.001 \\
$\quad \mathrm{n}=65$ & $\mathrm{n}=56$ & $\mathrm{n}=4$ & $\mathrm{n}=5$ & \\
$\begin{array}{l}\text { Pre-Placement OSCE } \\
\text { Active stations (SD) }\end{array}$ & $66.58(10.36)$ & $63.88(14.43)$ & $57.11(12.82)^{* *}$ & 0.007 \\
$\mathrm{n}=190$ & $\mathrm{n}=164$ & $\mathrm{n}=12$ & $\mathrm{n}=14$ & \\
\hline
\end{tabular}

*Independent t-test indicates significant difference in active station marks achieved in students who passed placement and students who struggled, $p=0.008$. $* *$ Independent t-test indicates significant difference in active station marks between students who passed placement and those who failed; overall $p=<0.001$, post- placement $p=0.001$ pre-placement $p=0.002$ 
Table 4: Mean passive station marks and placement outcome

\begin{tabular}{|lcccc|}
\hline $\begin{array}{l}\text { Mean Passive } \\
\text { Station marks }\end{array}$ & $\begin{array}{c}\text { Passed } \\
\text { placement }\end{array}$ & $\begin{array}{c}\text { Struggled on } \\
\text { placement }\end{array}$ & $\begin{array}{c}\text { Failed } \\
\text { placement }\end{array}$ & $\begin{array}{c}\mathrm{P} \\
\text { value }\end{array}$ \\
\hline Overall passive station mean (SD) & $61.30(9.26)$ & $59.18(9.26)$ & ${ }^{*} 57.41(9.31)$ & .050 \\
$\quad \mathrm{~N}=325$ & $\mathrm{n}=280$ & $\mathrm{n}=22$ & $\mathrm{n}=26$ & \\
$\begin{array}{l}\text { Post-placement OSCE } \\
\text { Passive stations (SD) }\end{array}$ & $62.56(8.39)$ & $57.60(9.41)$ & ${ }^{* *} 54.69(6.89)$ & .003 \\
$\quad \mathrm{n}=65$ & $\mathrm{n}=116$ & $\mathrm{n}=10$ & $\mathrm{n}=12$ & \\
$\begin{array}{l}\text { Pre-Placement OSCE } \\
\text { Passive stations (SD) }\end{array}$ & $60.41(9.76)$ & $58.50(9.71)$ & $59.75(10.67)$ & .795 \\
$\quad \mathrm{n}=190$ & $\mathrm{n}=164$ & $\mathrm{n}=12$ & $\mathrm{n}=14$ & \\
\hline
\end{tabular}

* Independent t-test indicates significant difference in overall passive station marks between students who passed placement and those who failed, $p=0.042 * *$ Independent t-test indicates significant difference in post- placement passive station marks between students who passed placement and students who failed placement, $p=0.003$ 
Table 5: Student evaluation of the OSCE examination

\begin{tabular}{|lccccc|}
\hline & \multicolumn{5}{c|}{ Percentage of students who agree that the OSCE } \\
\cline { 2 - 6 } & $\begin{array}{c}\text { Is a } \\
\text { meaningful } \\
\text { assessment } \\
\text { of skills }\end{array}$ & $\begin{array}{c}\text { Is a } \\
\text { fair } \\
\text { assessment of } \\
\text { skills }\end{array}$ & $\begin{array}{c}\text { Helps to } \\
\text { prepare } \\
\text { students for } \\
\text { practice }\end{array}$ & $\begin{array}{c}\text { Is } \\
\text { perceived } \\
\text { to be } \\
\text { stressful }\end{array}$ & $\begin{array}{c}\text { Will help } \\
\text { students } \\
\text { manage } \\
\text { stressful events }\end{array}$ \\
\hline $\begin{array}{l}\text { OSCE Post-placement } \\
\text { 2006/7 to 2009//10 }\end{array}$ & $63 \%$ & $73 \%$ & $35 \%$ & $83 \%$ & $40 \%$ \\
(n=140) & $(93 / 140)$ & $(104 / 140)$ & $(54 / 140)$ & $(116 / 140)$ & $(56 / 140)$ \\
$\begin{array}{l}\text { OSCE Pre-placement } \\
\text { 2010/11 to 2016/17 }\end{array}$ & $92 \%$ & $92 \%$ & $82 \%$ & $89 \%$ & $81 \%$ \\
$(\mathrm{n}=172)$ & $(160 / 172)$ & $(158 / 172)$ & $(141 / 172)$ & $(155 / 172)$ & $(140 / 172)$ \\
\hline
\end{tabular}

